\title{
(C) OPEN ACCESS \\ Use of cholesterol and soluble tumour markers CEA and syndecan-2 in pleural effusions in cases of inconclusive cytology
}

\author{
Miklos Gulyas, ${ }^{\oplus 1}$ Janos Fillinger, ${ }^{2}$ Andras D Kaposi, ${ }^{\circledR 3}$ Miklos Molnar ${ }^{4}$
}

\begin{abstract}
${ }^{1}$ Immunology, Genetics and Pathology, Rudbeck Laboratory, Uppsala University, Uppsala, Sweden

${ }^{2}$ Department of Pathology and Cytology, Korányi Nationa Institute for Pulmonology, Budapest, Hungary ${ }^{3}$ Department of Biophysics and Radiation Biology, Semmelweis University, Budapest, Hungary ${ }^{4}$ Institute of Pathophysiology, Semmelweis University, Budapest, Hungary
\end{abstract}

\section{Correspondence to} Dr Miklos Gulyas, Immunology, Genetics and Pathology, Rudbeck Laboratory, Uppsala University, Uppsala Se-75185, Sweden; miklos.gulyas@igp. uu.se

ADK and MM contributed equally.

Received 8 December 2018 Revised 5 March 2019 Accepted 6 April 2019 Published Online First 26 April 2019
ABSTRACT

Aims In order to improve diagnostics in pleural effusions, additional value of effusion cholesterol, carcinoembryonic antigen (CEA) and syndecan-2 assays to cytology was studied.

Methods Biomarkers were measured in effusion supernatants from 247 patients, of whom 126 had malignant pleural involvement, and their additional diagnostic efficacy to cytology was assessed.

Results Syndecan-2 measurement, although gave detectable concentrations in all effusions with highest median value in mesotheliomas, was non-discriminative between different pathological conditions. CEA concentrations exceeding $5 \mathrm{ng} / \mathrm{mL}$ cut-off point indicated carcinomas, regardless of pleural involvement, which gave a sensitivity of $62 \%$ and specificity of $100 \%$ for carcinoma. Cholesterol concentration over $1.21 \mathrm{mmol} / \mathrm{L}$ cut-off value indicated neoplastic pleural involvement with $99 \%$ sensitivity and 'merely' $69 \%$ specificity, the latter mainly due to raised levels being associated also with benign inflammatory effusions. Combined CEA and cholesterol determinations increased the sensitivity for diagnosing carcinomatosis from $70 \%$ with cytology alone to $84 \%$ and established the correct diagnosis in 16 of 31 carcinomatosis cases with inconclusive cytology. Cholesterol measurement alone, with elevated level, in combination with absence of substantial number of inflammatory cells in effusion sediment proved to be a magnificent marker for neoplastic pleural involvement with $99 \%$ efficacy, and recognised all 36 such cases with inconclusive cytology.

Conclusions Simultaneous measurement of CEA and cholesterol concentrations in effusion, or at least cholesterol alone, in combination with non-inflammatory fluid cytology, provides additional specific information about neoplastic pleural involvement, and can therefore be used as an adjunct to cytology, above all, in inconclusive cases.

\section{INTRODUCTION}

Tumour diagnosis in pleural fluid is based primarily on effusion cytology. However, conventional cytological examination of pleural effusion many times gives inconclusive result: beside malignant and benign diagnoses, numerous cases are equivocal, 'suspicious for malignancy'. ${ }^{1-3}$ In pleural irritations caused by inflammation, liver cirrhosis, irradiation and chemotherapy it is often difficult to discriminate shed reactive mesothelial cells from well differentiated cancer cells. In addition, cytology is frequently false negative, as result of low effusion volume with small yield and/or poor preservation of tumour cells. Consequently, a specific cytological diagnosis may have a sensitivity of only $43 \%-80 \% .^{13-5}$ Samples which are inconclusive due to some cellular atypia can be investigated further by auxiliary morphological techniques, such as immunocytochemistry ${ }^{126}$ and DNA cytometry, ${ }^{127}$ although these methods are of little help when only a small number of tumour cells available conserved.

Biochemical indicators, such as concentrations of cholesterol ${ }^{8-12}$ and carcinoembryonic antigen $(\mathrm{CEA})^{3} 4^{4}$ 13-15 in the serous effusions, have been studied as markers of malignancy. Such tests can be carried out in adequately stored fluids after cytological examination quickly. In a previous study we investigated the contribution of ascitic fluid levels of cholesterol and CEA to cytology. ${ }^{16}$ In the thoracic cavity, compared with the peritoneal cavity, other cancers and benign conditions are prevalent, for example, lung cancers, mesothelioma, tuberculosis and purulent inflammations versus gastrointestinal tumours, liver cirrhosis and pancreatitis, which may affect cut-off values and diagnostic performance.

Syndecan-2 (fibroglycan) is a cell surface proteoglycan associated with mesenchymal tissues. ${ }^{17} \mathrm{We}$ have described first high expression of syndecan-2 in mesothelioma cells both on messenger RNA and protein levels, shown also by immunocytochemistry. ${ }^{18}$ To the best of our knowledge, beside two pilot attempts with semiquantitative assessment in arbitrary units, ${ }^{19}{ }^{20}$ the quantitative concentrations of syndecan-2 in pleural fluid have not been measured to date.

In the present study we investigated on a large cohort $(n=247)$ the possible additional value of effusion cholesterol and CEA assays to pleural fluid cytology-in particular, in inconclusive cases. Diagnostic utility of syndecan- 2 concentrations was also assessed in a subset of these effusions $(n=179)$. The presence of pleural malignancy was established with histology using immunohistochemical panels.

\section{MATERIALS AND METHODS Patients}

In this study we investigated pleural effusions of 247 patients (147 men, aged $22-88$ years and 100 women, aged 23-88 years), who were admitted to Korányi National Institute for Pulmonology in Budapest, Hungary. The effusions were submitted for cytological examination. Pleural fluids without additives were prospectively and consecutively collected in different time periods between 2005 
and 2012. Samples were centrifuged for $\times 600 \mathrm{~g}$ for $10 \mathrm{~min}$ without delay and cell free supernatants were stored at $-80^{\circ} \mathrm{C}$ until assay. Measurements were made regularly when a certain number of samples have accumulated.

According to inclusion criteria, the definitive diagnosis of malignant involvement of the pleura by mesothelioma or metastatic tumours was established on thoracoscopic or ultrasound guided transthoracic lung/pleural biopsies or resection specimens with histopathology, supported by immunohistochemistry with at least four antibodies. The immunohistochemical panel included the following antibodies: TTF1, p40, CD15 or BerEP4, calretinin, podoplanin, WT1, STAT6, CD34, MIB1, napsin A, synaptophysin, CK20, CDX2, and sometimes other tissue-specific markers, as well. p16 FISH analysis was used occasionally in differentiating malignant mesothelioma and benign mesothelial proliferation. Paramalignant effusions caused by cancers without pleural involvement, that is, without presence of clear malignant cells in the pleural fluid were all based on histopathology of the tumour, negative pleural radiology (CT, MRI, positron emission tomography), direct pleural biopsy with negative histology, or negative necropsy within 1 year from sampling. Patients with non-malignant disease caused pleural effusions were followed up for at least a year and excluded if any type of malignancy was diagnosed or they deceased without necropsy, within 1 year from sampling. Tuberculous pleural effusion was diagnosed by identification of acid-fast bacteria (Löwenstein culture, Ziehl-Neelsen staining or PCR in the pleural fluid and/or caseous granulomas in pleural biopsy specimen and/or positive QuantiFERON-TB Gold Plus-test in blood with favourable clinical course after antituberculous therapy. Purulent pleurisy and empyema were verified by radiology, and typical symptoms with cough and fever that toned down with antibiotic treatment.

\section{Effusion cytology}

Conventional cytological examination of pleural effusions was done on Giemsa stained smears and H\&E stained cytospin sediments. Occasional immunocytochemical examination was carried out with antibodies as listed above. The evaluation was accomplished by three experienced cytopathologists (JF, EB, MG) using three diagnostic categories: benign (negative), inconclusive ('borderline', 'suspicious for malignancy') and malignant (positive). When calculating sensitivity, specificity and predictive values, only 'malignant' was considered abnormal, because inconclusive cytology was implicated with the 'negatives'.

\section{Tumour markers assay}

Aliquots from supernatant were taken for chemical analysis. Total cholesterol was measured enzymatically, using a colorimetric analysis adapted for the autoanalyser system (Technicon RA-100, Tarrytown, New York, USA). CEA was determined by a two-stage sandwich enzyme linked immunosorbent assay, using mouse and goat monoclonal antibodies (Test kit: GWB-FB64BF, GenWay Biotech, San Diego, CA, USA). Syndecan-2 was measured quantitatively in a subset of pleural fluids $(n=179)$, adapted from a semiquantitative procedure, ${ }^{19}$ and using monoclonal primary anti-human antibody developed in rat (LS-C39400) and secondary syndecan-2 polyclonal anti-human antibody developed in rabbit (LS-C39399). Both antibodies were purchased from Lifespan Biosciences, Seattle, Washington, USA. All assays were run in triplicate, at least.
Table 1 Aetiology of pleural effusions

\begin{tabular}{|c|c|c|c|}
\hline \multirow[b]{3}{*}{ Pleural effusions } & \multicolumn{3}{|c|}{ Number of patients } \\
\hline & \multirow[b]{2}{*}{ Total } & With & Without \\
\hline & & \multicolumn{2}{|c|}{ Neoplastic pleural involvement } \\
\hline Total & 247 & 126 & 121 \\
\hline Benign & 95 & 0 & 95 \\
\hline Non-inflammatory & 58 & 0 & 58 \\
\hline Congestive heart failure & 42 & 0 & 42 \\
\hline Liver cirrhosis & 6 & 0 & 6 \\
\hline Irritation, others* & 9 & 0 & 9 \\
\hline Nephrotic syndrome & 1 & 0 & 1 \\
\hline Inflammatory & 37 & 0 & 37 \\
\hline Purulent pleurisy/empyema & 21 & 0 & 21 \\
\hline Tuberculous pleurisy & 16 & 0 & 16 \\
\hline Malignancy-associated & 152 & 126 & 26 \\
\hline Carcinomas & 130 & $106(68)$ & $24(13)$ \\
\hline Lung & 100 & $81(51)$ & $19(11)$ \\
\hline Adenocarcinoma & 57 & $48(34)$ & $9(9)$ \\
\hline Squamous cell & 20 & $14(6)$ & $6(1)$ \\
\hline Large cell & 7 & $7(4)$ & 0 \\
\hline Small cell & 16 & $12(7)$ & $4(1)$ \\
\hline Breast & 10 & $10(6)$ & 0 \\
\hline Colorectal & 7 & $6(6)$ & $1(1)$ \\
\hline Ovarian & 4 & $4(1)$ & 0 \\
\hline Gastric & 2 & $1(1)$ & $1(1)$ \\
\hline Cervical & 2 & $2(2)$ & 0 \\
\hline Pancreatic & 1 & $1(1)$ & 0 \\
\hline Renal & 1 & 0 & 1 \\
\hline Prostatic & 1 & 0 & 1 \\
\hline Gall bladder & 1 & 1 & 0 \\
\hline Uterine choriocarcinoma & 1 & 0 & 1 \\
\hline Malignant mesothelioma & 17 & 17 & 0 \\
\hline Other malignancies $\dagger$ & 5 & 3 & 2 \\
\hline
\end{tabular}

Neoplastic cases are listed also by presence or absence of pleural involvement, and proportion of them producing carcinoembryonic antigen $(\geq 5 \mathrm{ng} / \mathrm{mL}$ ) is shown in parentheses.

*Pleural thickening: two cases.

tLymphoma: three cases, melanoma: two cases.

\section{Statistical analysis}

Cut-off limits for chemical analyses were calculated by receiver operating characteristics (ROC), maximised for diagnostic efficacy. The independence of the true diagnosis and the classification by the test used was checked by $\chi^{2}$ statistics at a rejection value of $\mathrm{p}<0.05$

\section{RESULTS}

\section{Patient characteristics}

Aetiology of the effusions is shown in table 1. Of the 247 patients, 95 showed no sign of neoplastic disease, the cause for the benign pleural fluid being partly non-inflammatory consisting of congestive heart failure (42 cases), liver cirrhosis (six cases), pleural irritation comprising also pancreatitis and pleural thickening (nine cases) and one nephrotic syndrome. Benign inflammatory effusions involved purulent pleurisy and empyema (21 cases), and tuberculous pleurisy (16 cases). The remaining 152 patients had a malignancy. Of 126 patients with malignant involvement of the pleura, 106 had a carcinoma accompanied by pleural carcinomatosis, 17 had mesothelioma and three had other malignancies: two lymphomas and one 


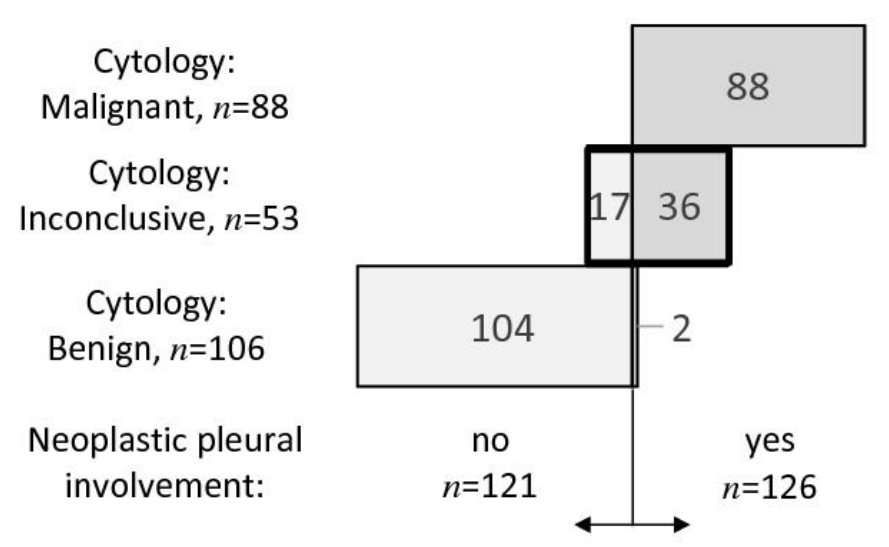

Figure 1 Effusion cytological evaluation ( $n=247)$ versus neoplastic involvement of the pleura determined by histology $(n=126)$.

melanoma. In 26 cancer cases with paramalignant effusion, the pleural fluid resulted from primary or metastatic tumour in the lung and/or mediastinal lymph nodes, with no malignant involvement of the pleura at histology and/or necropsy.

\section{Effusion cytological evaluation}

Of the 106 cases classified by effusion cytology as benign (negative), 104 were correctly identified as non-neoplastic with regard to pleural involvement of a tumour, but two were

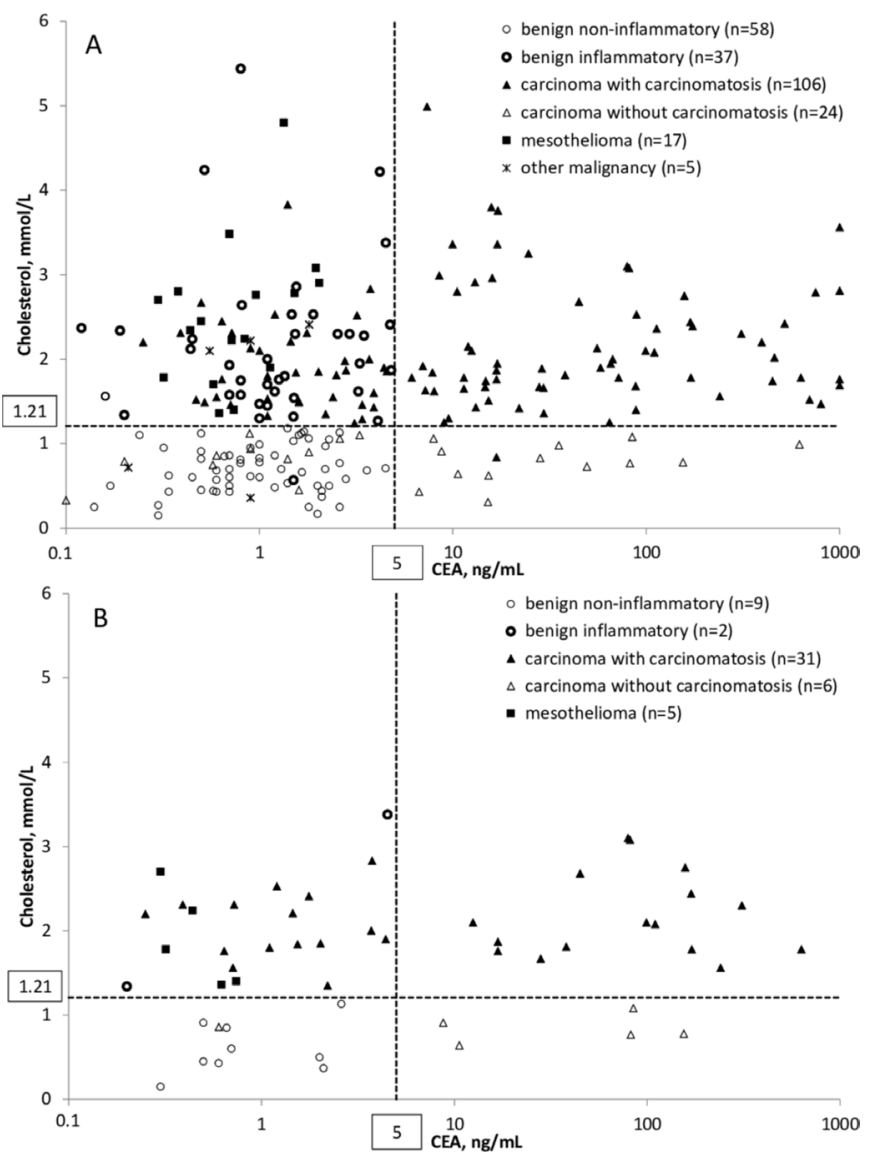

Figure 2 Concentrations of carcinoembryonic antigen (CEA) and cholesterol in pleural effusions. (A) All 247 cases. (B) Cases with inconclusive effusion cytology $(n=53)$. Number of cases in different diagnostic groups is shown in parentheses. Cut-off values for the two analyses are marked as broken lines. false negative (figure 1). In 20 of these 106 cases, tumours (18 carcinomas, one melanoma and one lymphoma) were found in the lung and/or lymph nodes, without involvement of the pleura. All 88 cases with malignant effusion cytology had neoplastic pleural involvement caused by carcinoma (carcinomatosis), mesothelioma or other malignancies. In 53 cases $(21 \%)$, the cytological report was inconclusive. Thirty-six of these proved to have malignant pleural involvement (five mesotheliomas and 31 carcinomas) on later biopsy or necropsy, six had carcinoma without carcinomatosis, whereas no tumour was found in the remaining 11 inconclusive cases. In effusion cytology purulent pleurisy was represented with abundance of neutrophil granulocytes and tuberculous pleurisy by pronounced lymphocytosis.

\section{CEA concentrations in pleural effusions}

The distribution and covariation of CEA and cholesterol levels is shown in figure 2 . All the 81 cases with raised CEA concentrations above the $5 \mathrm{ng} / \mathrm{mL}$ cut-off value had a carcinoma; the specificity of CEA for carcinoma was 100\% (95\% CI 96.9 to 100$)$ whereas the sensitivity was $62.3 \%(95 \% \mathrm{CI}$ 53.4 to 70.7 ), regardless of whether the pleura was involved. Although CEA production is the most common in gastrointestinal cancers, it also occurs in various other types of carcinomas, especially adenocarcinomas and, in 81 cases the secretion of CEA was sufficient to raise the values above the cut-off point (table 1). Of the 100 lung carcinomas 62 had elevated CEA levels in effusion, comprising 43 pulmonary adenocarcinomas, seven squamous cell carcinomas, four large cell carcinomas and eight small cell carcinomas. In 13 carcinoma cases with raised CEA concentration there was no carcinomatosis; however, high CEA values were more common in carcinomas with pleural involvement. All 22 non-epithelial neoplasms, comprising 17 mesotheliomas and five other malignancies, had low CEA levels. Diagnostic performance of CEA assay (figure $3 \mathrm{~A}, \mathrm{~B}$ ) shows that at optimal cut-off point of $5 \mathrm{ng} / \mathrm{mL}$ a moderate (54\%) sensitivity and a relatively high $(89.3 \%)$ specificity is obtained for malignant pleural involvement (table 2).

\section{Cholesterol concentrations in pleural effusions}

While a raised CEA level is seen not only in pleural carcinomatosis, but rather indicates a CEA producing carcinoma, an increased cholesterol concentration in pleural effusion seems to be a sign of neoplastic pleural involvement (figure 2). Beside nearly all carcinomas accompanied with carcinomatosis (105 cases), all the 17 mesotheliomas and three of other malignancies with pleural involvement (two lymphomas and one melanoma) had elevated cholesterol levels. The optimum diagnostic efficacy is obtained with a threshold of $1.21 \mathrm{mmol} / \mathrm{L}$ (figure $3 \mathrm{C}$ ), and a near-by cut-off point is obtained for the cytologically inconclusive cases (figure $3 \mathrm{E}$ ). At this cut-off point, malignancies with or without pleural involvement can be well enough separated from each other (figure 2), providing a sensitivity of $99.2 \%$ and a specificity of $69.4 \%$ for carcinomatosis or neoplastic involvement of the pleura (table 2, figure $3 \mathrm{~A}$ ). Raised cholesterol concentrations, however, are also seen in benign effusions, mostly in inflammatory conditions involving the pleura (37 cases), being either purulent or tuberculous pleurisy. The only benign case with elevated cholesterol level and non-inflammatory cytology was a nephrosis syndrome (figure 2). 


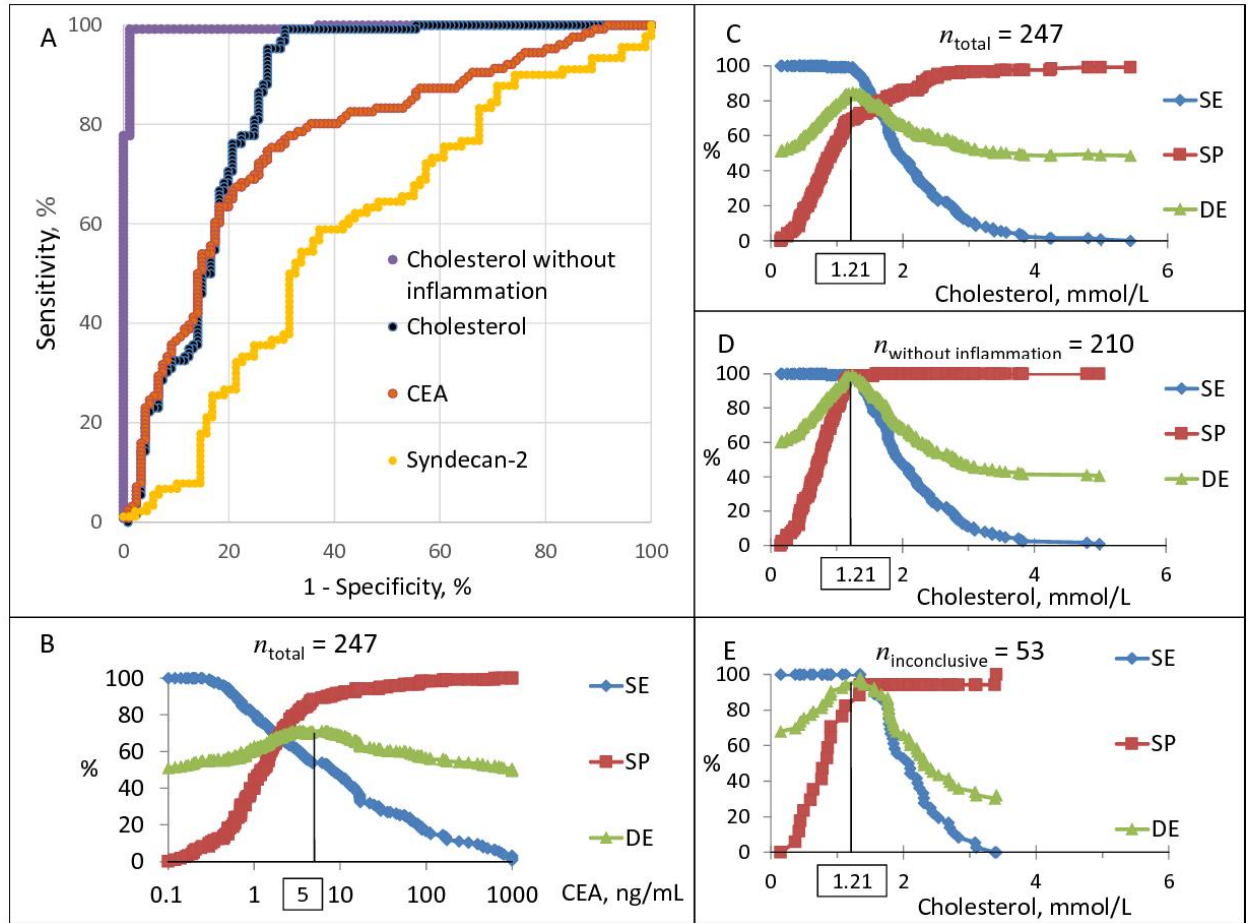

Figure 3 Performance of carcinoembryonic antigen (CEA), cholesterol and syndecan-2 analyses as a measure to detect neoplastic pleural involvement. (A) ROC curves, with best diagnostic performance obtained for cholesterol by subpopulation without pleural inflammation ( $\mathrm{n}=210$, purple) as compared with total material ( $n=247$, blue). (B-E) Diagnostic efficacy (DE), sensitivity (SE) and specificity (SP) of CEA (B) and cholesterol (CE) assays as a function of cut-off values. (C) All 247 cases, (D) subpopulation without pleural inflammation $(n=210)$, and (E) subset with inconclusive effusion cytology $(n=53)$. The optimal cut-off point of $1.21 \mathrm{mmol} / \mathrm{L}$ is the same for the two main groups and fitting also for the cytologically inconclusive cases.

\section{Simultaneous measurement of CEA and cholesterol in pleural effusions}

Simultaneous rise in cholesterol and CEA concentrations in pleural effusion was specific for carcinomatosis (figure 2), and this combination add diagnostic value (table 2) by increasing the sensitivity of the specific diagnosis of carcinomatosis from $69.8 \%$ with cytology alone to $84.1 \%$. In 16 of the 31 carcinomatosis cases with inconclusive effusion cytology, both markers exceeded the respective cut-off values, indicating neoplastic pleural involvement caused by a carcinoma, that is, carcinomatosis (figure 2B). This yields a $51.6 \%(95 \% \mathrm{CI}$ 33.1 to 69.9 ) diagnostic sensitivity among inconclusive cases. Five cases with inconclusive cytology had raised CEA values alone, suggestive of a carcinoma not yet accompanied by carcinomatosis. All five mesotheliomas with borderline effusion cytology and no substantial admixture of inflammatory cells had elevated cholesterol levels, while the two purulent pleurisy cases with inconclusive cytology had both raised cholesterol values and presence of numerous neutrophils in effusion sediment. Among the cases with negative effusion cytology $(n=106)$, the two false negatives, which turned out to have pleural carcinomatosis, have been detected by the simultaneous increase in cholesterol and CEA (figure 1).

\section{Cholesterol concentration combined with assessment of inflammatory cells in effusion sediment}

Figure 3A shows ROC curves of cholesterol assay of the total material $(n=247)$ compared with subpopulation without pleural inflammation $(n=210)$. The latter gives at the same threshold magnificent diagnostic performance with high efficacy (99\%), separating almost completely malignancies with and without pleural involvement (figures 2 and 3D, table 2). This implies that elevated cholesterol levels, in combination with non-inflammatory effusion cytology, indicate malignant involvement of the pleura, comprising also mesotheliomas and other malignancies, and have recognised all 36 tumour-involved pleura cases with inconclusive cytology.

\section{Syndecan-2 concentrations in pleural effusions}

Figure 4 shows distribution of syndecan- 2 concentrations in pleural fluids. There were detectable levels exceeding $0.9 \mathrm{ug} / \mathrm{mL}$ in all effusions, with no obvious separation between different pathological conditions (see also figure 3A). High levels also occurred in benign non-inflammatory conditions, of which a nephrosis syndrome had the highest value. The highest median value was obtained by the relatively small mesothelioma group with all concentrations exceeding $10 \mathrm{ug} / \mathrm{mL}$. Comparison of syndecan-2 levels in the whole cohort $(n=179)$ with that of the subpopulation with inconclusive effusion cytology cases $(n=29$, not shown) does not seem to add any distinctive information.

\section{DISCUSSION}

Occurrence of tumour cells in effusion sediment can be seen only in neoplastic involvement of the pleura, but the sensitivity of detecting such cells by cytology is restricted, owing to inadequate fluid volume with low cellular yield or bad conservation of cells. Another problem is that benign mesothelial cells may show signs of growth stimulation, that can mimic malignancy, and the induced 'mesotheliosis' is sometimes difficult to distinguish from tumour cells by routine cytology alone. These issues 
Table 2 Diagnostic values of cytology, cholesterol, carcinoembryonic antigen (CEA), and their combined use in distinguishing between 126 pleural effusions from patients with malignant involvement of the pleura and 121 cases without neoplastic pleural involvement

\begin{tabular}{|c|c|c|c|c|}
\hline Assays & $\begin{array}{l}\text { Definition of } \\
\text { abnormality }\end{array}$ & $\begin{array}{l}\text { Sensitivity \%, } \\
(\mathrm{n} / \mathrm{N}) \\
(95 \% \mathrm{Cl})\end{array}$ & $\begin{array}{l}\text { Specificity \%, } \\
(\mathrm{n} / \mathrm{N}) \\
(95 \% \mathrm{Cl})\end{array}$ & $\begin{array}{l}\text { Efficacy \%, } \\
(\text { n/N) } \\
(95 \% \text { Cl) }\end{array}$ \\
\hline Cytology & $\begin{array}{l}\text { Malignant } \\
\text { cytology* }\end{array}$ & $\begin{array}{l}69.8(88 / 126) \\
(61.0 \text { to } 77.7)\end{array}$ & $\begin{array}{l}100.0 \\
(121 / 121) \\
(97.0 \text { to } 100.0)\end{array}$ & $\begin{array}{l}84.6(209 / 247) \\
\text { (79.5 to 88.9) }\end{array}$ \\
\hline Cholesterol & $\begin{array}{l}\text { Raised } \\
\text { cholesterolt }\end{array}$ & $\begin{array}{l}99.2(125 / 126) \\
\text { (95.7 to } 100.0)\end{array}$ & $\begin{array}{l}69.4(84 / 121) \\
\text { (60.4 to } 77.5)\end{array}$ & $\begin{array}{l}84.6(209 / 247) \\
\text { (79.5 to 88.9) }\end{array}$ \\
\hline CEA & Raised CEA & $\begin{array}{l}54.0(68 / 126) \\
(44.9 \text { to } 62.9)\end{array}$ & $\begin{array}{l}89.3(108 / 121) \\
(82.3 \text { to } 94.2)\end{array}$ & $\begin{array}{l}71.3(176 / 247) \\
\text { (65.2 to } 76.8)\end{array}$ \\
\hline $\begin{array}{l}\text { Combined } \\
\text { cholesterol and } \\
\text { CEA }\end{array}$ & $\begin{array}{l}\text { Raised } \\
\text { cholesteroltand } \\
\text { CEA }\end{array}$ & $\begin{array}{l}53.2(67 / 126) \\
(44.1 \text { to } 62.1)\end{array}$ & $\begin{array}{l}100.0 \\
(121 / 121) \\
(97.0 \text { to } 100.0)\end{array}$ & $\begin{array}{l}76.1(188 / 247) \\
\text { (70.3 to 81.3) }\end{array}$ \\
\hline $\begin{array}{l}\text { Cytology and/ } \\
\text { or combined } \\
\text { cholesterol and } \\
\text { CEA }\end{array}$ & $\begin{array}{l}\text { Malignant } \\
\text { cytology* } \\
\text { and/or raised } \\
\text { cholesterol† } \\
\text { and CEA }\end{array}$ & $\begin{array}{l}84.1(106 / 126) \\
\text { (76.6 to 90.0) }\end{array}$ & $\begin{array}{l}100.0 \\
(121 / 121) \\
(97.0 \text { to } 100.0)\end{array}$ & $\begin{array}{l}91.9(227 / 247) \\
\text { (87.8 to } 95.0)\end{array}$ \\
\hline $\begin{array}{l}\text { Cholesterol } \\
\text { without } \\
\text { inflammation }\end{array}$ & $\begin{array}{l}\text { Raised } \\
\text { cholesterolt } \\
\text { and non- } \\
\text { inflammatory } \\
\text { cytology§ }\end{array}$ & $\begin{array}{l}99.2(125 / 126) \\
\text { (95.7 to } 100.0)\end{array}$ & $\begin{array}{l}98.8(83 / 84) \\
\text { (93.5 to } 100.0)\end{array}$ & $\begin{array}{l}99.0(208 / 210) \\
(96.6 \text { to } 99.9)\end{array}$ \\
\hline
\end{tabular}

*Malignant diagnoses: 'positives' only, inconclusive cytology incorporated with 'negatives'.

tCut-off point for cholesterol: $1.21 \mathrm{mmol} / \mathrm{L}$

‡Cut-off point for CEA: $5 \mathrm{ng} / \mathrm{mL}$.

$\S$ Non-inflammatory cytology: no substantial presence of neutrophils or lymphocytes in effusion sediment.

$\mathrm{Cl}$, confidence interval.

contribute to the number of inconclusive cytological reports of a 'borderline lesion'.

Syndecan-2, also called fibroglycan, is a cell surface (transmembrane) proteoglycan mainly expressed in cells of mesenchymal origin. ${ }^{17}$ Syndecan-2 expression has been noted in benign mesothelial cells, ${ }^{21}$ neuronal cells, ${ }^{22}$ keloids and hyperplastic scars, ${ }^{23}$ fibrotic dermal and lung tissues, ${ }^{24}$ as well as fibrosarcoma cells. ${ }^{25}$ We have described first the high expression of syndecan-2 in mesothelioma cells as compared with adenocarcinoma cells, detected also by flow-cytometry and immunocytochemistry. ${ }^{18}$ To our knowledge, so far this is the first trial with quantitative measurement of syndecan-2 levels in pleural effusions. We got measurable concentrations in all effusions. The highest median value was obtained by the mesothelioma group with all its cases exceeding a concentration of $10 \mathrm{ug} / \mathrm{mL}$. There were, however, high levels also in different pathological conditions, thus the distribution of syndecan-2 concentrations by itself does not seem to help in distinguishing these groups. One explanation for the difference of syndecan-2 expression in various cell types versus effusions may relate to cellular distribution of this proteoglycan. In mesothelioma cells abundant syndecan-2 presence was detected in the cytoplasm, ${ }^{18}$ whereas the concentrations in cellfree pleural effusions may represent shed syndecan-2, which has also been described being raised in high-grade cancers ${ }^{25-27}$ and other conditions. ${ }^{23}$ The possible utility of measuring syndecan-2 concentrations in pleural effusions in various pathological conditions, involving also idiopathic pulmonary fibrosis, ${ }^{28}$ remains to be further investigated.

Increased concentrations of CEA are generated in some carcinomas, mainly adenocarcinomas, and this oncofetal antigen can be tracked in blood-serum and effusions. ${ }^{13}{ }^{15}$ We have found raised effusional CEA levels beside adenocarcinomas in a few squamous cell, large cell and small cell carcinomas of the lung, which is in line with increased serum levels described in the literature. ${ }^{29} 30$ Elevated CEA concentrations in effusions have been described in carcinomas with ${ }^{343-16}$ and without carcinomatosis. ${ }^{1631-34}$ The underlying mechanism in the latter case, that is, in paramalignant effusion, is most often due to massive mediastinal lymph node metastases. In the present study 13 carcinoma cases without pleural carcinomatosis had increased effusional CEA values (figure 2), and five of them had inconclusive changes on effusion cytology. These morphological changes can be interpreted by non-malignant growth stimulation and proliferation, although case of macroscopically unrevealed metastases ${ }^{35}$ cannot be ruled out.

Elevated concentration of cholesterol in effusions is more specifically related to exudates, caused by neoplastic or inflammatory involvement of the serous membrane. In neoplastic process cholesterol may originate from cell membranes or cytosol, as a result of disintegration of tumour cells and/or nearby benign serosal cells. ${ }^{1236}$ It can also derive from the plasma and interstitial space, as a result of vascular leakage caused by obstructed lymph vessels and/or increased permeability of the affected serous membrane. ${ }^{12}{ }^{37}$ One source of cholesterol in inflammatory effusion may be degeneration of leucocytes, that is, the prima facie inflammatory cells, which contain large quantities of this lipid. ${ }^{123}$ Disintegration of serosal cells and/or increased permeability can also occur in massive inflammatory conditions involving the serous membrane, ${ }^{12}{ }^{37}$ but these are accompanied with abundant presence of neutrophils or lymphocytes in the effusion sediment, that can easily be detected by cytology. High cholesterol levels in this manner, in combination with non-inflammatory effusion cytology, are therefore most common in association with neoplastic pleural involvement, as represented by high sensitivity and specificity (figures 2 and 3A,D, table 2).

Diagnosis of a malignant condition in the pleural cavity needs maximal specificity to be useful in the clinical praxis. Effusion cytological examination is the first line monitoring that yields a correct diagnosis in most cases with carcinomatosis or neoplastic pleural involvement, however, some samples are reported as inconclusive. Cholesterol value in pleural effusion over $1.21 \mathrm{mmol} / \mathrm{L}$ is 'alone' a sensitive, though not entirely specific marker for carcinomatosis or neoplastic pleural involvement, while CEA levels exceeding $5 \mathrm{ng} / \mathrm{mL}$ can mark a carcinoma. These two chemical assays measure different effects of tumours, such as CEA production versus cell disintegration, and when they were combined, simultaneous increases in both parameters were specific for carcinomatosis, improving the sensitivity of 'single' effusion cytology from $69.8 \%$ to $84.1 \%$ (figure 2, table 2). By this means the correct diagnosis could be established in a number (16/31) of carcinomatosis cases with inconclusive effusion cytology. Measurement of both cholesterol and CEA concentrations in pleural fluid thus adds information to the cytological diagnosis, although elevated cholesterol level solely, with complementary information concerning presence or absence of substantial number of inflammatory cells in effusion sediment overwrite this, providing a superb tool for indication of neoplastic pleural engagement with $99 \%$ diagnostic efficacy (figures 2 and $3 \mathrm{~A}$ and D). Thereby all 36 tumour-involved pleura cases with inconclusive effusion cytology were recognised, comprising also mesotheliomas. The use of cholesterol as a single chemical parameter can primarily be applied or at least interpreted by cytopathologists, because they see both the accidental admixture of abundant number of inflammatory cells in 


\section{Original article}

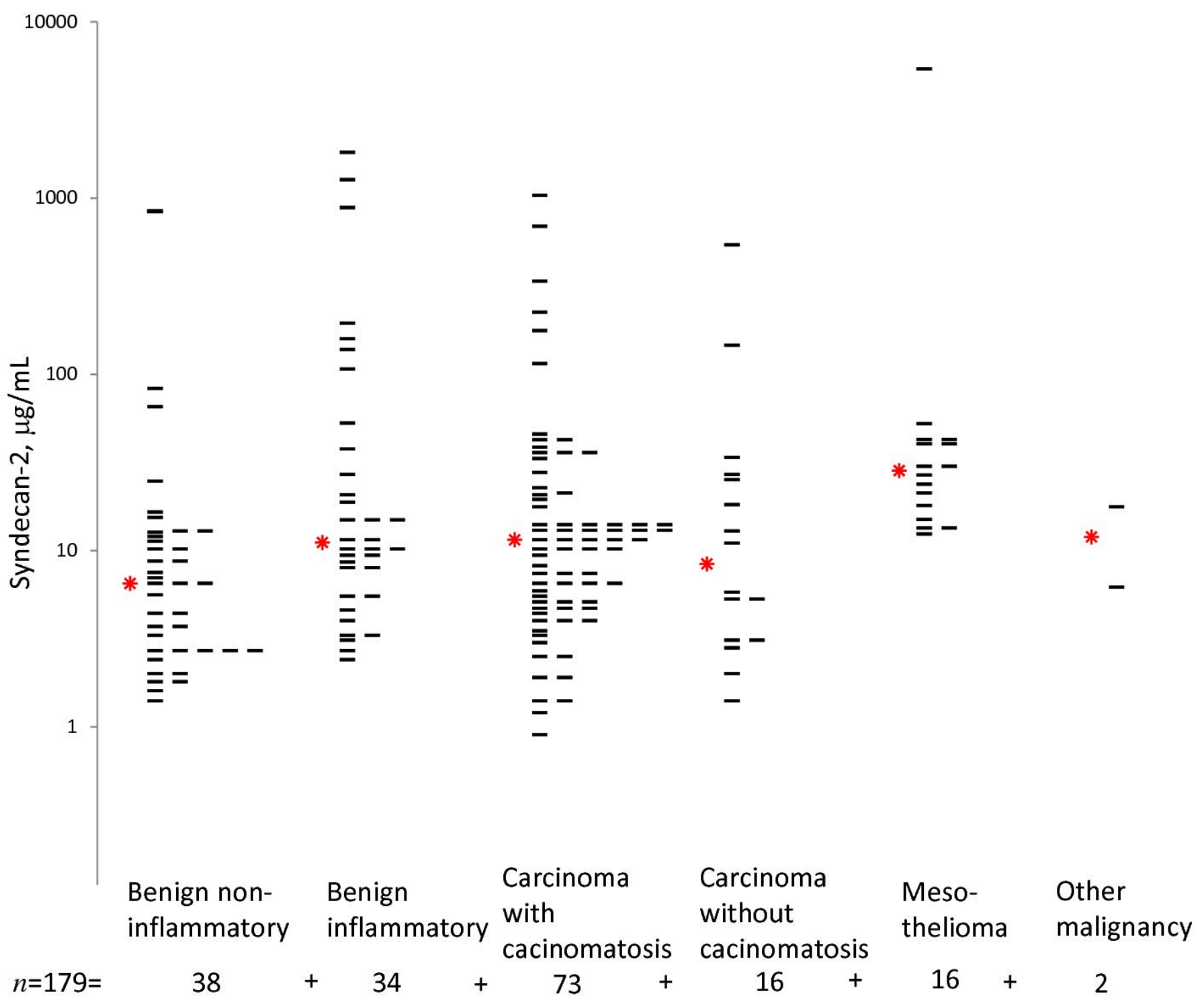

Figure 4 Concentrations of syndecan-2 in pleural effusions from 179 patients with different pathological conditions. Asterisks mark median values in each group.

effusion sediments for excluding these cases, and the occurrence of inconclusive, 'borderline', 'suspicious for malignancy' cells.

\section{CONCLUSIONS}

The results of the present study show, that quantitative measurement of syndecan-2 in pleural fluid, although gave detectable concentrations in all effusions with highest median value in

\section{Take home messages}

Effusional carcinoembryonic antigen (CEA) concentration over $5 \mathrm{ng} / \mathrm{mL}$ indicates carcinoma, regardless of pleural involvement.

- Cholesterol level over $1.21 \mathrm{mmol} / \mathrm{L}$ marks neoplastic or inflammatory pleural involvement.

- Combined CEA and cholesterol assays increase sensitivity of cytology for carcinomatosis.

- Elevated cholesterol concentration with non-inflammatory cytology indicates neoplastic pleural involvement. mesotheliomas, was non-discriminative between different pathological conditions.

Simultaneous measurement of CEA and cholesterol concentrations in pleural effusion, or at least cholesterol alone, in combination with non-inflammatory fluid cytology, provides additional specific information about neoplastic pleural involvement, and can therefore be used as an adjunct to cytology, above all, in inconclusive cases. This renders an effective assistance primarily for cytopathologists, thereby evading the need for another thoracocentesis.

Correction notice This article has been corrected since it was published Online First to resolve formatting errors.

Handling editor Tahir S Pillay.

Acknowledgements The authors are indebted to Dr Éva Badár for doing cytological diagnostics and her kind cooperation.

Contributors All authors ( $M G, J F, A D K, M M)$ were involved in the conception and/ or design of the study. JF and MG participated in the collection or generation of the study data. MM contributed with laboratory analysis, reagents and tools. ADK was lead statistician of the project, reviewed and provided input for the reporting of the results. MG led the design and initiation of the project and served as a project 
supervisor throughout. MG, MM, ADK and JF were involved in the analyses and/ or interpretation of the data. All authors read, reviewed and approved the present manuscript.

Funding This study was supported in part by grants from the Hungarian Kidney Foundation and Research Fund of Uppsala County Council (ALF), Sweden.

Competing interests None declared.

Patient consent for publication Not required.

Ethics approval This manuscript reports a retrospective study of routinely collected samples conducted under approval of Korányi National Institute for Pulmonology (227/2004-IV/1).

Provenance and peer review Not commissioned; externally peer reviewed.

Data sharing statement Data are available upon reasonable request.

Open access This is an open access article distributed in accordance with the Creative Commons Attribution Non Commercial (CC BY-NC 4.0) license, which permits others to distribute, remix, adapt, build upon this work non-commercially, and license their derivative works on different terms, provided the original work is properly cited, appropriate credit is given, any changes made indicated, and the use is non-commercial. See: http://creativecommons.org/licenses/by-nc/4.0/.

\section{REFERENCES}

1 Motherby H, Friedrichs N, Kube M, et al. Immunocytochemistry and DNA-image cytometry in diagnostic effusion cytology. II. Diagnostic accuracy in equivocal smears Anal Cell Pathol 1999;19:59-66.

2 Hanselaar AGJM. Additional techniques in serous effusions. Anal Cell Pathol 2002;24:1-4. Review.

3 Antonangelo L, Sales RK, Corá AP, et al. Pleural fluid tumour markers in malignant pleural effusion with inconclusive cytologic results. Curr Oncol 2015;22:336-41.

4 Pinto MM. CA-15.3 assay in effusions: comparison with carcinoembryonic antigen and CA-125 assay and cytologic diagnosis. Acta Cytol 1996;40:437-42.

5 Motherby H, Nadjari B, Friegel P, et al. Diagnostic accuracy of effusion cytology. Diagn Cytopathol 1999;20:350-7. Jun.

6 Sundling KE, Cibas ES. Ancillary studies in pleural, pericardial, and peritoneal effusion cytology. Cancer Cytopathol 2018;126 Suppl 8(Suppl 8):590-8. Aug.

7 Kundu R, Handa U, Mohan H. Role of DNA flow cytometry and immunocytochemical analysis in diagnosis of malignant effusions. Diagn Cytopathol 2012;40:887-92.

8 Hamm H, Brohan U, Bohmer R, et al. Cholesterol in pleural effusions. A diagnostic aid. Chest 1987:92:296-302

9 Heffner JE, Brown LK, Barbieri CA. Diagnostic value of tests that discriminate between exudative and transudative pleural effusions. Primary study Investigators. Chest 1997;111:970-80.

10 Gázquez I, Porcel JM, Vives M, et al. Comparative analysis of light's criteria and other biochemical parameters for distinguishing transudates from exudates. Respir Med 1998:92:762-5.

11 Leers MPG, Kleinveld HA, Scharnhorst V. Differentiating transudative from exudative pleural effusion: should we measure effusion cholesterol dehydrogenase? Clin Chem Lab Med 2007:45:1332-8.

12 Hamal AB, Yogi KN, Bam N, et al. Pleural fluid cholesterol in differentiating exudative and transudative pleural effusion. Pulm Med 2013;2013:1-4.

13 Hernández L, Espasa A, Fernández C, et al. CEA and CA 549 in serum and pleural fluid of patients with pleural effusion. Lung Cancer 2002;36:83-9.

14 Villena V, López-Encuentra A, Echave-Sustaeta J, et al. Diagnostic value of CA 549 in pleural fluid. Comparison with CEA, CA 15.3 and CA 72.4. Lung Cancer 2003:40:289-94.

15 Lee JH, Chang JH. Diagnostic utility of serum and pleural fluid carcinoembryonic antigen, neuron-specific enolase, and cytokeratin 19 fragments in patients with effusions from primary lung cancer. Chest 2005;128:2298-303.
16 Gulyás M, Kaposi AD, Elek G, et al. Value of carcinoembryonic antigen (CEA) and cholesterol assays of ascitic fluid in cases of inconclusive cytology. J Clin Pathol 2001;54:831-5.

17 David G, Bai XM, Van der Schueren B, et al. Spatial and temporal changes in the expression of fibroglycan (syndecan-2) during mouse embryonic development. Development 1993:119:841-54.

18 Gulyás M, Hjerpe A. Proteoglycans and WT1 as markers for distinguishing adenocarcinoma, epithelioid mesothelioma, and benign mesothelium. J Pathol 2003;199:479-87.

19 Seidel C, Gulyás M, David G, et al. A sandwich ELISA for the estimation of human syndecan-2 and syndecan-4 in biological samples. J Pharm Biomed Anal 2004;34:797-801.

20 Mundt F, Nilsonne G, Arslan S, et al. Hyaluronan and N-ERC/mesothelin as key biomarkers in a specific two-step model to predict pleural malignant mesothelioma. PLoS One 2013:8. eCollection 2013.

21 Gulyás M, Dobra K, Hjerpe A. Expression of genes coding for proteoglycans and Wilms' tumour susceptibility gene 1 (WT1) by variously differentiated benign human mesothelial cells. Differentiation 1999;65:89-96.

22 Ethell IM, Yamaguchi Y. Cell surface heparan sulfate proteoglycan syndecan-2 induces the maturation of dendritic spines in rat hippocampal neurons. J Cell Biol 1999;144:575-86.

23 Mukhopadhyay A, Wong MY, Chan SY, et al. Syndecan-2 and decorin: proteoglycans with a difference--implications in keloid pathogenesis. J Trauma 2010;68:999-1008.

24 Ruiz XD, Mlakar LR, Yamaguchi Y, et al. Syndecan-2 is a novel target of insulinlike growth factor binding protein-3 and is over-expressed in fibrosis. PLoS One 2012:7:e43049.

25 Park H, Han I, Kwon HJ, et al. Focal adhesion kinase regulates syndecan-2-mediated tumorigenic activity of HT1080 fibrosarcoma cells. Cancer Res 2005;65:9899-905.

26 Park H, Kim Y, Lim Y, et al. Syndecan-2 mediates adhesion and proliferation of colon carcinoma cells. J Biol Chem 2002;277:29730-6.

27 Choi S, Choi Y, Jun E, et al. Shed syndecan-2 enhances tumorigenic activities of colon cancer cells. Oncotarget 2015;6:3874-86.

28 Tsoyi K, Chu SG, Patino-Jaramillo NG, et al. Syndecan-2 attenuates radiation-induced pulmonary fibrosis and inhibits fibroblast activation by regulating PI3K/AKt/ROCK pathway via CD148. Am J Respir Cell Mol Biol 2018;58:208-15.

29 Wang L, Wang D, Zheng G, et al. Clinical evaluation and therapeutic monitoring value of serum tumor markers in lung cancer. Int I Biol Markers 2016;31:80-7.

30 Lei L, Chen Q, Wang Z, et al. Usefulness of carcinoembryonic antigen in the diagnosis of small cell lung cancer combined with adenocarcinoma. Adv Clin Exp Med 2017;26:1091-4.

31 Ferrer J, Villarino MA, Encabo G, et al. Diagnostic utility of CYFRA 21-1, carcinoembryonic antigen, CA 125, neuron specific enolase, and squamous cell antigen level determinations in the serum and pleural fluid of patients with pleural effusions. Cancer 1999:86:1488-95.

32 Gaspar MJ, De Miguel J, García Díaz JD, et al. Clinical utility of a combination of tumour markers in the diagnosis of malignant pleural effusions. Anticancer Res 2008;28:2947-52.

33 Hsieh T-C, Huang W-W, Lai C-L, et al. Diagnostic value of tumor markers in lung adenocarcinoma-associated cytologically negative pleural effusions. Cancer Cytopathol 2013:121:483-8.

34 Enz N, Fragoso F, Gamrekeli A, et al. Carcinoembryonic antigen-positive pleural effusion in early stage non-small cell lung cancer without pleural infiltration. J Thorac Dis 2018;10:E340-E343.

35 Ammon A, Eiffert $\mathrm{H}$, Reil S, et al. Tumor-associated antigens in effusions of malignant and benign origin. Clin Investig 1993:71:437-44.

36 Spady DK, Dietschy JM. Sterol synthesis in vivo in 18 tissues of the squirrel monkey, guinea pig, rabbit, hamster, and rat. J Lipid Res 1983;24:303-15.

37 Valdés L, San-José E, Estévez JC, et al. Cholesterol in pleural exudates depends mainly on increased capillary permeability. Trans/ Res 2010:155:178-84.

38 Klock JC, Pieprzyk JK, Cholesterol PJK. Cholesterol, phospholipids, and fatty acids of normal immature neutrophils: comparison with acute myeloblastic leukemia cells and normal neutrophils. J Lipid Res 1979;20:908-11. 